\title{
IMPLICAÇÓES DA REGULAÇÃO DISCURSIVA NA LEITURA DE IMAGENS EM NARRATIVA INFANTIL
}

\section{IMPLICATIONS OF DISCURSIVE'S REGULATION IN READING IMAGES FROM THE CHILD NARRATIVE}

\author{
Lélia Erbolato Melo ${ }^{1}$ \\ Universidade de São Paulo/USP
}

\begin{abstract}
RESUMO
O objetivo principal, neste artigo, é enfatizar as implicações da regulação discursiva na leitura de imagens em sequência por crianças, a interação entre os códigos verbal e não verbal (Cosnier et Brossard, 1984), e os efeitos da tutela do adulto na narrativa oral infantil (Bruner, 1991), entre outros, levando em consideração aspectos linguísticos e discursivos. Os resultados são apresentados e discutidos com exemplos extraídos de pesquisa realizada.
\end{abstract}

PALAVRAS-CHAVE: regulação discursiva; imagens; narrativa.

\section{ABSTRACT}

This article aims to emphasize the implications of discursive regulation adult in reading images in sequence from the child oral literature, the interaction between verbal and nonverbal codes (Cosnier et Brossard, 1984), and the effects tutelage adult in children's oral narrative (Bruner, 1991), among others, taking into consideration linguistic and discursive aspects. The results are presented and discussed with examples from research conducted.

KEYWORDS: discursive regulation; reading images; narrative.

1 Doutora em Lingüística Geral/ Paris IV, e Livre-Docente em Psicolinguística/ USP, leliaerbolato@ hotmail.com 


\section{INTRODUÇÃO}

:

O tema central neste artigo é a leitura de imagens em crianças de 5, 8 e 10 anos de idade de uma escola pública de São Paulo. O objetivo principal é examinar o papel da regulação discursiva do adulto e seus efeitos na construção de narrativa infantil. Para Caron (1983), este tipo de regulação é entendido como um conjunto de intervenções discursivas que permitem à atividade de se desenvolver segundo as intenções dos interlocutores. Quanto aos objetivos específicos, eles levam em conta pressupostos como: imprevisibilidade, no ato de narrar; criatividade quanto à competência de manter uma temática; identificação de personagens, de acontecimentos, entre outros. Concluindo nossa proposta: estamos admitindo a possibilidade de uma variação na atividade de narrar, uma vez que pode ocorrer uma apropriação, por parte da criança, do ponto de vista linguístico, cognitivo e cultural. A narrativa, por um lado, aparece como um lugar de encontro das dimensões afetivas e cognitivas. Por outro lado, ela se constrói numa certa coerência dialógica, em função dos saberes e das expectativas do interlocutor, e por produzir efeitos discursivos no ouvinte-leitor.

Neste contexto, serão levados em conta, a partir de agora, alguns pressupostos teóricos pertinentes. Assim, a abordagem converge inicialmente para os seguintes temas e autores: narrativa (Bruner e François); memória e lembrança (Ricoeur); imagem (Davallon); imagem e pensamento (Sartre); percepção e imaginação (Saes).

* Narrativa: Bruner (1996: 60) cita dois lugares comuns, que resistiram ao longo do tempo, no sentido de criar uma sensibilidade à narrativa. $\mathrm{O}$ primeiro lugar consiste em dizer como uma criança deveria "ser sensibilizada" pelos mitos, pelas histórias, pelas narrativas populares, pelas histórias de suas culturas. O segundo lugar comum diz que a ficção desenvolve a 'imaginação'.

Bruner (1997: 46-48) propõe três características para o estudo da narrativa. A propriedade principal, para o autor, talvez, seja a sequencialidade: uma narrativa é composta por uma sequência singular de eventos, estados mentais, ocorrências, envolvendo seres humanos como personagens ou autores. A segunda característica é que ela pode ser 'real' ou 'imaginária', sem perder sua força como história. A terceira característica que torna a narrativa um instrumento popular é o fato de estabelecer ligações entre o excepcional e o comum. 
Bruner (2005: 28; 47; 113) enfatiza que "as histórias são, ao mesmo tempo, a moeda e a divisória de uma cultura, no sentido figurado de que a cultura molda e determina nossas expectativas". Conforme o autor, "graças à narrativa, reconstruímos, e, de certa maneira, reinventamos o presente e o futuro". Enfim, "ao longo desse processo, memória e imaginação se misturam".

F. François (2009: 35; 39), "todo locutor está às voltas com a linguagem, a língua, e as relações 'intersubjetivas’. Conforme o autor, “... não existe uma teoria da narrativa, mas uma teoria da narrativa que não afasta a fala infantil das análises e que, muitas vezes, faz parte dela, para pensar a natureza da atividade narrativa".

* Memória e lembrança: Ricoeur (2010: 40-42), em "Esboço fenomenológico da memória", apresenta inicialmente duas observações interessantes sobre o tema memória. A primeira observação apresenta os fenômenos atribuídos à memória, no discurso comum, o discurso da vida cotidiana. A segunda observação propõe esboçar uma fenomenologia fragmentada, cujo último fio condutor continua sendo a relação com o tempo. Distingue, na linguagem (p.41), a memória como visada e a lembrança como coisa visada. Para o autor, a memória está no singular, e as lembranças estão no plural. Ricoeur (2010) sugere também uma série de pares oposicionais, para o estudo da narrativa. O primeiro par de oposições (p.43) é constituído pela dupla, hábito e memória, e algumas restrições devem ser feitas sobre as principais características de ambos. O segundo par de oposições (p.45-46) é constituído pela evocação/busca. Por "evocação", o autor entende o aparecimento atual de uma lembrança, denominada de mnémê, designando por anamnesis "busca ou recordação". O esforço de recordação pode ter sucesso ou fracassar. À recordação bem-sucedida, Ricoeur denomina de memória "feliz".

*Imagem: Davallon (1999: 27-31) lembra que a imagem, enquanto operador social de memória, "representa a realidade, mas pode também conservar a força das relações sociais, e fará, então, impressão sobre o espectador". Aponta duas características semióticas para a eficácia simbólica da imagem. Em primeiro lugar, uma imagem pode ser compreendida ou recebida segundo dois níveis diferentes, que possuem regras de funcionamento próprias. Incorpora, então, a referência a Benveniste, autor do artigo Semiótica (1969), que propõe dois modos de significação: um 
: semiótico, fundado sobre o reconhecimento de unidades de significação

: previamente definidas; e outro semântico, fundado sobre a compreensão do sentido do texto em sua totalidade e que inclui os mecanismos da enunciação (p.29). Em segundo lugar, a imagem é um operador de simbolização.

*Imagem e pensamento: Sartre (2010: 8-9; 44; 46; 98) enfatiza: (a) "O reconhecimento da imagem como tal é um dado imediato do senso íntimo". (b) "Uma coisa, porém, é apreender imediatamente uma imagem como imagem, outra é formar pensamentos sobre a natureza das imagens em geral". (c) "Uma vez percebidas, as imagens se fixam e se alinham na memória". (d) "A formação da lembrança é contemporânea da percepção". Finalmente, para o autor, sobre as relações da imagem com o pensamento, " a imagem serve para decifrar, compreender, explicar: mas será preciso primeiro decifrá-la, compreendê-la, explicá-la”.

*Percepção e pensamento: para Saes (2010: 9-10; 11-37), o conceito de percepção ora pende para o mais sensível (sensação, sensibilidade, ou intuição sensível), ora mais para o intelectual (campo das ideias e da intuição intelectual). Quanto ao conceito de imaginação, ele vem interligado aos itens imagem, imaginário, fantasia, e representação mental. A seguir, a autora apresenta um roteiro ilustrado de reflexões de pensadores sobre "como e o que" percebemos, da resposta mais antiga, como a de Aristóteles, a respostas modernas, para chegar às respostas contemporâneas de MerleauPonty e Wittgenstein.

\section{Metodologia}

A pesquisa foi realizada, em situação de narrativa oral interativa adulto/criança, com, e sem a tutela do adulto, num total de 18 crianças de 5, 8 e 10 anos de idade (meninos e meninas), que frequentam escola pública, em São Paulo. A coleta e a transcrição dos dados foram feitas por integrantes do Grupo de Pesquisa em Psicolinguística/GPPL-USP, sob minha coordenação. Os dados foram transcritos segundo as convenções utilizadas por Preti e Urbano (1990). As crianças selecionadas foram indicadas pelos professores, por atender aos critérios de inclusão (ausência de alterações e/ou histórico de fala, de audição, de visão e de desenvolvimento motor). A história selecionada, 'A trombada', extraída do livro 'Cabra-Cega' (Eva Furnari, 2003: 10-11), constituída de quatro imagens, sem texto, contando 
um episódio com começo, meio e fim, apresenta uma brincadeira divertida, entre duas personagens (um menino e uma menina), com o objetivo de trabalhar as noções de sequência temporal. Como fios condutores de observação são considerados os eventos de cada história narrada, e seus principais ingredientes contextuais (cenário; desenvolvimento; conflito; desfecho); a identificação e retificação das falsas crenças da personagem; a utilização dos liames causais dos acontecimentos; os tipos e efeitos da tutela do adulto.

1) Cenário: um menino e uma menina estão sentados no muro, e alguém está caminhando (evento1).

2) Desenvolvimento: duas personagens, um homem e uma mulher, usando óculos e chapéu, o homem tem uma pasta na mão direita, a mulher tem uma bolsa na mão direita, vira a cabeça para trás, cumprimenta as duas crianças que estão sentadas no muro (evento2).

3) Conflito: o homem e a mulher trombam, o chapéu da mulher cai no chão, a mulher pega a pasta do homem, as duas crianças que estão sentadas no muro se assustam (evento3).

4) Desfecho: o homem põe os óculos e o chapéu dela, segura com a mão direita a bolsa da mulher, a mulher põe os óculos e o chapéu dele, segura com mão direita a pasta do homem, os dois caminham em direção contrária, as duas crianças que estão sentadas no muro dão risada (evento4).

A coleta dos dados se desenvolveu em três situações. A) Visualização das imagens na tela do computador, uma após a outra, e em conjunto, e solicitação para a criança construir uma narrativa autônoma com imagens. B) Solicitação para a criança construir uma narrativa com tutela do adulto e com imagens. C) Solicitação para a criança construir uma narrativa sem tutela do adulto e sem imagens. O objetivo principal é verificar os efeitos do papel do adulto no ato de narrar da criança, quanto: (a) utilização da linguagem; (b) integração entre os elementos verbal e não verbal; (c) contraste entre as duas situações, que permite acompanhar melhor o que acontece na esfera do inteligível, do interpretável e do compreensível, conforme Orlandi (1993). Além desses pressupostos, e retomando Kail et Fayol (2004), verificamos que, no plano de recuperação das informações na memória, a lembrança de itens reagrupados em categorias tem um papel importante na continuidade da narração. 


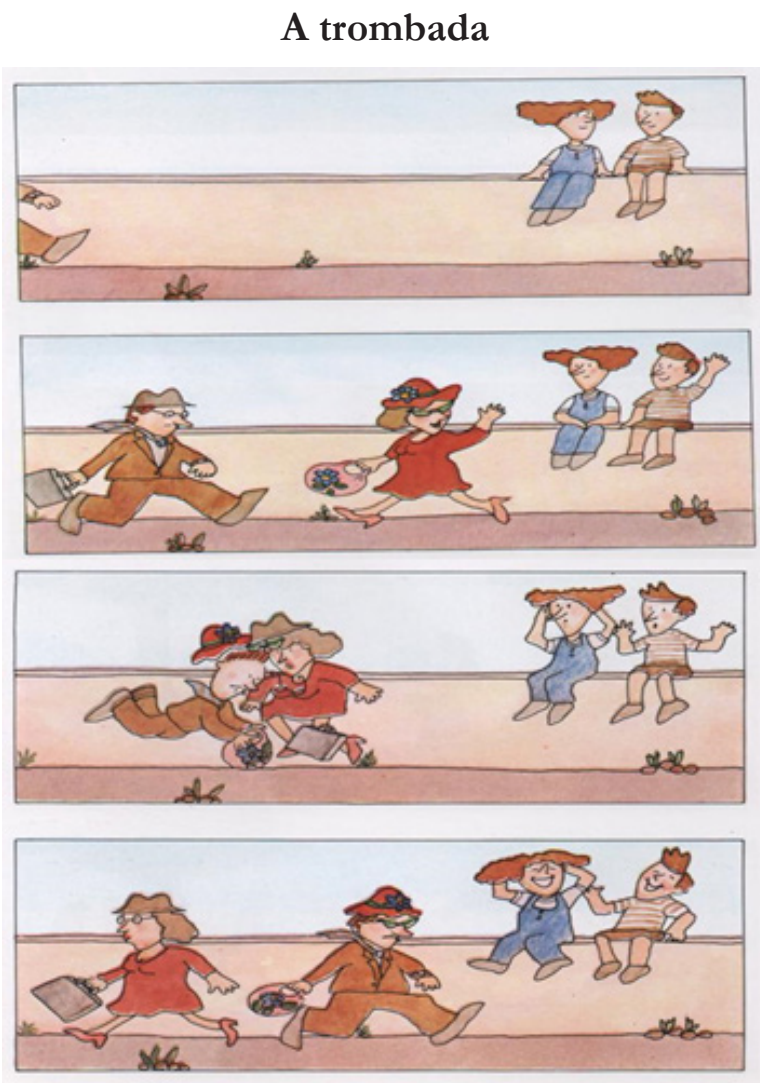

\section{Análise e interpretação dos resultados}

$\mathrm{Na}$ caracterização dos fios condutores da análise e interpretação dos resultados foi considerada a implicação de habilidades específicas de desempenho, que, de alguma forma, fornece subsídios para o desempenho cognitivo e social infantil. Partindo desses pressupostos, os dados coletados são observados, conforme as posições discursivas do adulto, por ocasião da construção da narrativa pela criança: (a) enquadramento da tarefa: etapa A); (b) orientação e regulação discursiva: etapa B); (c) aprovação e encorajamento para a realização da tarefa: etapa C). Neste sentido, são incorporados outros autores, com o objetivo de refletir sobre as intervenções discursivas, em situações de narrativa oral, quanto aos efeitos da tutela (Bruner, 1991), quando o adulto ajuda crianças de 3, 4 e 5 anos na construção de uma pirâmide, e da contratutela (F. François, 1996), 
quando o adulto é controlador, organizador, no sentido de 'mandar falar', ou 'ajudar a falar'. Enfim, para Veneziano \& Hudelot (2006: 13), [a tutela] : "parece funcionar como um catalisador de competências obstruídas em sua manifestação por pressões de funcionamento". Finalmente, quanto à questão 'interpretar'/'interpretação’ dos resultados, citamos Deniau (2015:25), “a interpretação é sempre reflexiva, uma retomada consciente do movimento da compreensão, uma vez que é interrompido, porque a indicação não é clara, ou porque é indeterminada".

\section{Exemplo 1 (J. 5 a. 10 m.)}

\section{A) Narrativa autônoma com imagens}

J: o menino e a menina tavam sentado... aí veio uma moça e um moço e deu um ou pra eles... aí depois...ela foi lá e bateu nu outro homem que tava na frente dela ...aí depois...

\section{B) Narrativa com tutela do adulto e com imagens}

P1: mas agora a gente vai ver juntinho tá?...vamos ver essa história junto...na primeira figura quem é aqui?

J1: um menino e a menina sentada

P2: isso... e aí o que acontece...quem chega?

J2: esse homem e essa mulher

P3: uhn...quem é ele?... quem é esse homem?

J3: esse que tava indu pra lá e essa mulher tava indu pra cá... aí eles bateram

P4: uhn ...e nessa trombada quando eles bateram o que aconteceu?

J4: os meninos falaram... ou...ou... api eles continuaram a andá

P5: uhn...por que será que eles estão rindo aqui?

J5: porque eles são felizes

P6: por que eles são felizes... tem alguma coisa diferente aqui?

J6: (balança a cabeça que sim)

P7: o quê? 
J7: é que ela tá nervosa e ele também...

P8: e aqui tem alguma coisa diferente?

J8: (balança a cabeça que sim)

P9: o quê?

J9: que ele tá nervoso

P10: quem que tava com esse chapéu aqui?

J10: (aponta o dedo para a imagem)

P11: ela? ...é ...e por que será que eles estão rindo então?

J11: porque ele tá com o chapéu dela e ela tá com o chapéu dele

\section{C) Narrativa sem tutela do adulto e sem imagens}

P12: muito bem...então agora eu vou pedir pra você me contar de novo essa bistória...

J12: u menino e a menina tava sentada né? ... aí ...aí o homem e a moça...aí depois eles bateram nu... aí... aí o menino falou ou ou ... aí depois ... eles...eles ficaram nervoso e os menino...o menino e a menina ficaram rindo...porque o homem tava com o chapéu dela e ela com o chapéu dele

Comentário. Na etapa B), o sujeito (P1), depois de estabelecer um vínculo com o sujeito (J1), na tentativa de envolvê-lo na situação apresentada ("vamos ver essa história junto"), inicia um diálogo com ele ("... quem é aqui"). A partir da solicitação, o sujeito (J1) responde brevemente à solicitação ("um menino e a menina sentada"), e motiva a continuidade do diálogo entre o adulto e a criança.

Assim, diante da concordância de (P1) ao pedido enfático de esclarecimento do adulto (P2) ("isso... e aí o que acontece... quem chega?"), o sujeito (J2) limita-se a responder ("esse homem e essa mulher").

$\mathrm{Na}$ sequência, a solicitação insistente de esclarecimento de (P3) ("uhn...quem é ele?...quem é esse homem?"), por sua vez, leva (J3) a recorrer ao uso do paralelismo, reutilizando estruturas, com diferentes conteúdos, e de pró-formas adverbiais (pra) lá e (pra) cá ("esse que tava indu pra lá e essa mulher tava indu pra cá...aí eles bateram”), que acabam favorecendo a encenação ou teatralização no ato de narrar o fato. 
O sujeito (P4), por sua vez, com o objetivo de manter a situação de interação discursiva, dá continuidade à tutela reflexiva sobre o episódio : da 'trombada', e o que aconteceu, quando eles ( $=_{\mathrm{O}}$ homem e a mulher) 'bateram' (=trombaram). A resposta do sujeito (J4), com base na descrição dos fatos, mantém a agilidade da narrativa, na medida em que se estabelece uma relação articulada ("os meninos falaram...eles continuaram a andá"), a fim de justificar as ações 'falar/andar'. Neste sentido, a utilização inicial do sinal de escuta, em (P4 e P5) ("uhn”), e as sucessivas e insistentes indagações, em busca de esclarecimentos, em (P4, P5 e P6) (“...o que aconteceu?”); (“por que eles estão rindo aqui?”); (“...tem alguma coisa diferente aqui?’), levam o sujeito a imprimir um movimento à fala (J4), a justificar a razão do riso (J5), e ao uso do gesto ilustrador de "balançar a cabeça", em sinal de concordância, mantém a comunicação interativa (J6).

Com isso, as perguntas reiterativas, em conexão com as diferentes manifestações do sujeito, ampliam o universo de envolvimento entre os interlocutores e a participação na troca interativa. São movimentos discursivos interligados entre si e em sintonia interativa. Finalmente, a solicitação insistente da pesquisadora, em (P5, P6, P7, P8 e P9), sobre a razão do riso do sujeito, leva os sujeitos, respectivamente a tomar algumas providências, como:

a) recorrer à justificação sucessiva, utilizando o tom emocional, ou enfático, de fala (J7 e J9), e de “apontar o dedo” (J10);

b) retomar a questão colocada no início por (P5), estabelecendo uma sintonia com (P11), a fim de obter um esclarecimento do uso do chapéu por (J11), reutilizando estruturas paralelas, com diferentes conteúdos ("porque ele tá com o chapéu dela e ela tá com o chapéu dele”);

c) combinar o estilo minimalista de interação discursiva, na medida em que (J5) acrescenta um tom emocional à sua fala ["porque eles são felizes”] e (J7) [“é que ela tá nervosa e ele também”].

Finalmente, diante da retomada enfática de (P9) (“o quê?"), e da confirmação do estado emocional de (J9) ("que ele tá nervoso"), o sujeito (P10), na tentativa de manter o diálogo, retoma a questão de quem está usando o chapéu, e leva o sujeito (J10), a recorrer ao uso expressivo do signo não verbal de "apontar o dedo"(Cosnier et Brossard, 1984). 
Uma vez esclarecida a situação, como (P10 não pretendia finalizar o : diálogo, ele retoma a questão anterior colocada no início por (P5), levando o sujeito (J11) a justificar o uso do chapéu e a reutilizar estruturas paralelas, com diferentes conteúdos ("porque ele tá com o chapén dela e ela tá com o chapén dele")".

Exemplo 2 (I. S. S. 8 a. 7 m.)

\section{A) Narrativa autônoma com imagens...}

I.S.S.: tinha dois amigos sentados no muro... aí chegaram outros duas pessoas ...aí...aí chegaram outras pessoas e essas pessoas acabaram se esbarrando nelas (desculpa)... aí depois essas pessoas que estavam sentadas no muro começaram a rir ...enquanto os outros foram embora ... eu acho que foi isso que entendi

\section{B) Narrativa com tutela do adulto e com imagens}

P1: vou mostrar pra você uma sequência de imagens que vão formar uma história ... aí enquanto eu vou mostrando você vai pensando na história e quando eu acabá de mostrar o vídeo ... aí você vai me contá essa história...tá bom?

\section{I.S.S.1: (mexe a cabeça que sim)}

P2: tá bom ...vamos começar ...oh...aqui oh...tem dois amigos sentados no muro e aí tá chegando outras pessoas...tá bom?

I.S.S.2: (mexe a cabeça que sim)

P3: então tá bom ... então agora vamos vê junto aí você vai me explicando tá?... então tá... aqui você falô que tavam chegando outras pessoas né?... e aí o que aconteceu?

I.S.S.3: aqui...essas duas pessoas chegaram uma e outra... e depois enquanto eles estavam indo embora essas pessoas que estavam sentadas no muro começaram a rir

P4: e ficou alguma coisa de diferente?

I.S.S.4: pra mim não

C) Narrativa sem tutela do adulto e sem imagens

P5: então tá bom... então agora você me conta a história tudo de novo 
I.S.S.5: tinha duas pessoas sentadas no muro e chegaram outras duas pessoas .... essas duas pessoas se esbarraram umas nas outras enquanto essas pessoas que se esbarraram foram embora...essas pessoas que estavam sentadas no muro começaram a rir

Comentário. Tomando como referência a produção discursiva inicial da criança (etapa A), observamos que, inicialmente, ela utiliza (a) argumentos justapostos sucessivos com 'aí'; (b) o pedido de 'desculpas', a fim de neutralizar simbolicamente um ato de esbarrão cometido contra pessoas; (c) inferências de pré-julgamento (“eu acho") e de compreensão ("foi isso que entendi").

A seguir, P1 e P2 (etapa B) instalam uma tutela reflexiva insistente, que solicita o cumprimento de procedimentos pela criança. Neste sentido, ao delimitar as ações da criança, o interlocutor adulto faz com que ela recorra, respectivamente, à comunicação não verbal de 'mexer com a cabeça' (I.S.S.1 e I.S.S.2), indicando um sinal de escuta. A solicitação de explicação e precisão do fato "e aí o que aconteceu”, e o uso da pró-forma adverbial, 'aqui', por (P3), leva I.S.S.3 a formular recategorizações lexicais de interpretação: (a) “essas duas pessoas chegaram..."; (b) “... enquanto eles estavam indo embora..."; (c) "essas pessoas... começaram a rir".

Concluindo, como o interlocutor adulto (P4), ainda não estava satisfeito, interroga a criança (I.S.S.4) "e ficou alguma coisa de diferente?", levando-a novamente a se posicionar na constituição da subjetividade, "pra mim não", como uma espécie de fecho da situação interativa, instaurando dessa forma "certa distância entre o sujeito da enunciação e o conteúdo do enunciado" (Kerbrat-Orecchioni, 2014: 89).

Exemplo 3 (M.E.P.S. 10 a. 1 m.)

\section{Narrativa autônoma com imagens}

M.E.P.S.: eles tavam sentado num muro... aí veio umas pessoa e sem querer se atrapalhou todo e caíram no chão...aí depois elas ficaram nervosa virou um pro outro e foi embora ... eles ficaram assustados porque eles pensaram que ia brigá ... mas aí eles já viram que era só uma bobagem 
B) Narrativa com tutela do adulto e com imagens

P1: ah::.....muito bem... então pera aí... você vai me ajudar a entender... então vamos lá... que que aconteceu aqui... aqui?

M.E.P.S.1: aqui eles estavam conversandu...aí passou uma pessoa dandu tchau ...e ela não tava vendu que o homi tava vindu...aí sem querer se atrapalhou todo o homi ficou nervoso e ela com vergonha ...aí ele se virô pro outro e foi embora...aí eles pensaram que ia brigá... mas foi só uma bobagem

P2: ah:::... os meninos pensaram que ele ia brigá de novo?

M.E.P.S.2: é os meninos pensaram que ele ia brigá de novo mas era uma bobagem

\section{C) Narrativa sem tutela do adulto e sem imagens}

P3: ah::....entendi...conta pra mim tudo de novo por favor

M.E.P.S.3: eles tavam eh::....eles tavam sentado no muro conversandu... aí de repente chega uma pessoa e deu tchau pra eles... mas ela olhou assim pra eles... eles não (viru) que veio outro homi... aí eles se atropelaram todo... aí eles ficaram nervoso e viraram um pro outro eh::.... foram embora... aí eles pensaram que ia brigá mas era uma bobagem

Comentário. A interação inicial do interlocutor adulto (P1) com o sujeito é feita através de uma tutela reflexiva inicialmente insistente (“... você vai me ajudar a entender... então vamos lá"), que termina com uma solicitação intensiva de esclarecimento (“... que que aconteceu aqui...aqui”).

Em sua resposta, (M.E.P.S.1) utiliza argumentos justapostos de forma integrada, i.e., articulados entre si, através do uso de 'aí (“...aí passou uma pessoa dando tchau... aí sem querer se atrapalhou todo o homi ficou nervoso e ela com vergonha... aí ele se virô pro outro e foi embora...”), que culminam com uma falsa crença, ou crença de segunda ordem (Perner \& Wimmer, 1985) (“aí eles pensaram que ia brigá...”), e um encadeamento reativo ("mas foi só uma bobagem").

O que ocorre na fala de (M.E.P.S.1) nos remete a Sartre (2010: 8-9), quando ele diz que "o reconhecimento da imagem como tal é um dado imediato do senso íntimo. Uma coisa, porém, é apreender imediatamente 
uma imagem, outra é formar pensamentos sobre a natureza das imagens em geral".

$\mathrm{Na}$ sequência, o interlocutor adulto (P2) recorre ao sinal de escuta ('ah'), e de hesitação em relação à fala anterior do sujeito (“...os meninos pensaram que ele ia brigá de novo?”). Neste momento, (M.E.P.S.2) confirma o que já havia dito antes e acrescenta um contraponto discursivo reativo ("é os meninos pensaram que ele ia brigá de novo mas era uma bobagem”).

Enfim, observamos que os exemplos citados sugerem três possibilidades de reflexão. 1) Os atos de linguagem são decorrentes de duas funções da regulação discursiva pelo adulto: a) uma função de apoio ("guidage"), que coordena os atos sucessivos pelos quais se constrói a situação discursiva; b) uma função de compensação (“compensation"), que corrige as manifestações (efetivas ou virtuais), introduzidas pela criança, ou os erros cometidos, conforme Caron (1983: 156). 2). A regulação discursiva adotada pelo adulto pode, ou não, contribuir com sucesso para o progresso linguageiro da criança. 3) A diversidade das formas de engajamento afetivo, cognitivo e estético da criança com a imagem favorece as relações intersubjetivas.

\section{Considerações Finais}

A análise das narrativas infantis confirma as reflexões de Joly (2005) que a leitura da imagem estimula a interpretação criativa e serve de apoio a evocações e questionamentos de suas significações. Neste sentido, "interpretar uma imagem exige essencialmente o uso das capacidades psicológicas comuns, isto é, do equipamento sensorial, emotivo e cognitivo particular" (Morizot, 2009: 21).

Os resultados obtidos pelas crianças, nas etapas A) e B), de narrativa autônoma e narrativa com tutela, ambas com visualização de imagens, contribuíram de modo significativo para a realização da etapa $\mathbf{C}$ ), de narrativa sem tutela e imagens, especialmente, quanto à organização da narrativa em função dos conteúdos, quando contrastada com o desempenho das crianças nas etapas A) e B), respectivamente. Verificamos também que eles sugerem que a imaginação, a percepção e a memória influenciam de forma significativa as produções linguageiras das crianças, e a seleção do que é dito na leitura/interpretação das imagens. 
Paralelamente, destacamos também o papel relevante dos processos : mentais que permeiam as relações entre linguagem (compreensão e produção) e situações de comunicação nas três etapas citadas. Eles sugerem e confirmam quatro observações a seguir (Melo, 2016: 37-38).

1) A interpretação de uma determinada imagem pressupõe essencialmente fazer uso de capacidades psicológicas comuns, isto é, do equipamento sensorial, emotivo e cognitivo do ser humano.

2) A imaginação, a percepção e a memória influenciam, de forma significativa, as produções linguageiras das crianças, na seleção do que deve ser dito na leitura/interpretação das imagens, e no encadeamento discursivo dos acontecimentos.

3) A leitura de imagens mobiliza três tipos de operações cognitivas que condicionam as produções linguageiras: a) identificação dos elementos representativos, animados e não animados; b) inferências dos acontecimentos identificados; c) sequenciação dos acontecimentos isolados.

4) O uso dos signos não verbais tem um papel importante na regulação e no controle do fluxo conversacional, quando se trata da criança de cinco anos de idade. Daí sua tendência para respostas curtas, quando se trata de cooperação argumentativa, ao contrário do que acontece com a criança mais velha que ousa um pouco mais para expressar seus julgamentos e se posicionar quanto: (a) à variação dos modos de organização da narrativa em função dos conteúdos; (b) à capacidade de retomada-modificação dos modelos culturais; (c) à diversidade das misturas individuais criativas de linguagem.

Concluindo, a análise da narrativa oral infantil constitui um desafio que deve continuar a ser explorado no âmbito da di-cotomia língua-linguagem. E também: que o cruzamento das inferências discursivas com a visualização das imagens favorece de modo significativo o fluxo da narrativa.

A expectativa é que sejam realizadas mais pesquisas com o olhar voltado para a sala de aula, que permitam identificar e contrastar os estilos, segundo seus traços peculiares.

\section{REFERÊNCIAS BIBLIOGRÁFICAS}

BRUNER, Jerome. Le développement de l'enfant: savoir faire, savoir dire, 3ème éd. Paris: Presses Universitaires de France, 1991. 
BRUNER, Jerome. L'éducation, entrée dans la culture. Les problèmes de l'école à la lumière de la psychologie culturelle. Traduzido do inglês por Yves Bonin. Paris: Retz, 1996.

BRUNER, Jerome. Atos de significação. Porto Alegre: Artes Médicas, 1997.

BRUNER, Jerome. Pouquoi nous racontons-nous des histoires? Traduzido do inglês por Yves Bonin. Paris: Retz, 2005.

CARON, Jean. Les régulations du discours. Psycholinguistique et pragmatique du discours. Paris: Presses Universitaires de France, 1983.

COSNIER, Jacques. Brossard, Alain. La communication non verbale. Neuchâtel/ Paris: Delachaux \& Niestlé, 1984.

DAVALLON, Jean. A imagem, uma arte de memória? in ACHARD, Pierre et al. Papel da memória. Tradução e Introdução de José Horta Nunes. Campinas, SP : Pontes, 1999: 23-37.

DENIAU, Guy. Qu'est-ce qu'interpréter. Paris: Vrin, 2015.

FRANÇOIS, Frédéric. Pratiques de l'oral. Dialogue, jeu et variations des figures du sens. Paris: Nathan, 1993.

FRANÇOIS, Frédéric. Crianças e narrativas. Maneiras de sentir, maneiras de dizer... Tradução e adaptação de Ana Lúcia Tinoco Cabral e Lélia Erbolato Melo. São Paulo: Humanitas, 2009.

FURNARI, Eva. A trombada, in Furnari, Eva, Cabra-Cega. São Paulo: Ática, 2003: 10-11.

JOLY, Martine. Introdução e análise da imagem. Tradução de Marina Appenzeller, $8^{\mathrm{a}}$ ed. Campinas, SP: Papirus, 2005.

KAIL, Michèle, FAYOL, Michel. L'acquisition du langage. Le langage en développement. Au-delà de trois ans, 2ème éd., vol.II. Paris: Presses Universitaires de France, 2004. 
: KERBRAT-ORECCHIONI, Catherine. Análise da conversação: princípios e

: métodos. Tradução de Carlos Piovezani Filho, $1^{\mathrm{a}}$ ed. (2a reimpressão). São Paulo: Parábola, 2014.

MELO, Lélia Erbolato (org.). Competência pragmática e linguística na leitura de imagens. Reflexões interdisciplinares. Curitiba: CRV. 2016.

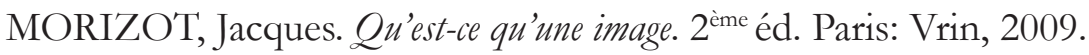

ORLANDI, Eni Pulcinelli. Discurso e leitura. 2a ed. São Paulo: Cortez, 1993.

PERNER, Josef, WIMMER, Heinz. "John thinks that Mary thinks that...: attribution of second-order beliefs by 5 - to 10-year-old children", Journal of Experimental Child Psychology, 1985, 39: 437-471.

PRETI, Dino, Urbano, HUDINILSON (orgs.). A linguagem falada culta na cidade de São Paulo. São Paulo: T.A.Queiroz/FAPESP, 1990.

RICOEUR, Paul. A memória, a história, o esquecimento. Tradução de Alain François [et al.]. Campinas, SP: Editora da UNICAMP, 2010.

SAES, Sílvia Faustino de Assis. Percepção e imaginação. São Paulo: Martins Fontes, 2010.

SARTRE, Jean-Paul. A imaginação. Tradução de Paulo Neves. Porto Alegre: L\&PM, 2010.

VENEZIANO, Edy, HUDELOT, Christian. États internes, fausse croyance et explications dans les récits: effets de l'étayage chez les enfants de 4 à 12 ans, Langage et l' Homme, 2006, 41 (2): 117-138. 